\title{
A CAPABILITIES ANALYSIS OF E-FULFILMENT BUSINESSES: TRANSFORMATION IN THE LOGISTICS INDUSTRY
}

\author{
Janice Burn \& Paul Alexander \\ School of Management Information Systems \\ Edith Cowan University \\ 100 Jooondalup Drive, Joondalup, Perth WA, Australia \\ Tel: 61863045244 \\ Fax: 61863045988 \\ p.alexander@ecu.edu.au \\ j.burn@ecu.edu.au
}

\begin{abstract}
:
This paper reports on the evaluation of practices of 48 leading e-fulfillment suppliers in the UK. Initial findings suggest that while a comprehensive model of e-fulfilment is validated these organisations are also providing services not previously recognised as e-fulfilment capabilities by the literature. This leads to the development of a staged model of transformation, which implies that the industry will embrace radical change in some sectors and lead to a new definition of e-fulfillment businesses. More in depth investigation leads to a proposed definition, and a methodology to measure the degree of transformation.
\end{abstract}

Keywords: e-fulfilment, logistics, virtual organisations, online retail, industry transformation, knowledge

\section{INTRODUCTION}

The online retail sector is already an important part of the global economy (Table I) and growing rapidly. This in turn has spawned another industry: e-fulfilment, dealing with all associated logistics, warehousing and delivery services. These services are estimated to be worth US\$1.006 Trillion in the US alone, or $10.1 \%$ of their GDP in 2000 (Rogers and Tibben-Lembke 2001). Furthermore, $21 \%$ of all logistics transactions are expected to be online in 2005, with the long-term possibility that traditional freight companies will ultimately cease to exist (Homs, Meringer et al. 2001). Clearly, not only is online retail a significant industry sector, but this growing area of e-fulfilment is set to lead a transformation in the whole area of storage and delivery services.

\begin{tabular}{|c|c|c|c|}
\hline \multicolumn{4}{|c|}{ Online Retail Sales Trends (fourth quarter comparisons) - US\$B } \\
\hline $\mathbf{2 0 0 0}$ & $\mathbf{2 0 0 1}$ & $\mathbf{2 0 0 2}$ & $\mathbf{2 0 0 3}$ \\
\hline 8.1 & 11.8 & 12.6 & 20.4 \\
\hline
\end{tabular}

Table I: Growth of US Online Retail, source (Greenspan 2003)

This paper explores the concepts which are encompassed in the term e-fulfilment, and presents a model of e-fulfilment activities based on the existing literature. The research study was conducted in three stages. Firstly, the authors completed an analysis of efulfilment capabilities of 48 UK-based third party e-fulfilment companies in 2003. The findings from this analysis lead to the development of a model of transformation for the industry as a whole. A more in-depth review of the 48 organisations focused on these extended capabilities and provided insight into future developments within the industry. 
Finally, four of these companies agreed to participate in a detailed review of ongoing and future services. The results promise to change the definition of e-fulfilment service providers. They also highlight the impact of e-business on industry strategies and suggest the need to explore multiple planning approaches within an overall vision of transformational alignment (Walters, 2004; Ash and Burn, 2003).

\section{THE SCOPE OF E-FULFILMENT.}

\section{The needs of online retailers}

Fulfilment for online retailers is recognised as incorporating physical, information and financial aspects of the value chain from supply through to ultimate delivery, and even product returns (Bussiek 1999). In the new context of globalisation and with increasing emphasis on reduction of time frames, the logistics which support the fulfilment process necessitate advanced information management and communication systems (Sauvage, 2003). Increasingly, the term "e-fulfilment" has been coined to represent this whole process (Pyke et al, 2000; Punakivi, 2002).

Prior research identifies the following characteristics within the scope of e-fulfilment (Barsh, Crawford et al. 2000; Pyke, Johnson et al. 2000; Colin 2001; Raman 2001):

- $\quad$ picking - selecting product (to be delivered) from warehouse shelves. Related issues are location design and picking systems;

- packing - specific packaging for delivery of products. This can include breaking original packages and repackaging. Often must be customised for each order;

- customer service - managing customer queries and complaints;

- financial transactions - calculating and including fulfilment costs, and electronically settling these with appropriate organisations;

- $\quad$ warehouse costs - associated with product storage;

- delivery - systems and delivery alliances;

- transport mechanisms and flows - using multiple delivery mechanisms to ensure deliveries arrive on time and undamaged

- procurement management - purchasing arrangements automatically (electronically) integrated with fulfilment suppliers, triggering delivery transactions;

- management information systems - concerned with integrating and managing all aspects of the process;

- front end (ordering) services - which electronically trigger the fulfilment process automatically from a web-purchaser's mouse-click;

- $\quad$ after-sales service - to ensure fulfilment problems are resolved;

- returns - manage reverse logistics related to incorrect, damaged or fit-foruse product issues. This must not only ensure convenient and quick return of goods, but often must initiate re-delivery (of the correct goods);

- real-time tracking - for management of all pools of product, and also commitment to "promises" made by front-end ordering systems.

These are recognised as integrated components that create virtual proximity between etrader and customer and cover everything a company does to satisfy customer demand within an e-commerce market (Menezes 1999). 


\section{A model based on capabilities}

Although components may be aligned with existing activities, e-fulfilment requires its own unique supply chains and distribution networks (DiMaria 2001). This is integral to the whole concept since the degree of integration between legacy logistics/delivery and supply chain systems must ensure end-to-end coordination and information sharing (Strader, Lin et al.). This need for partnerships sees the development of dynamic virtual collaboration networks and is spawning active transport-related research into "Collaborative Transportation Management" (CTM) and "Collaborative Planning, Forecasting and Replenishment" (CPFR) (Esper and Williams 2003). In addition, the nature of the product range, customer delivery expectations, and delivery zones have all changed in the e-tailing world and impacted the supply chains which support them (Rabinovich and Evers 2003). Brand new issues such as product returns, last-mile delivery and remote payments must now be addressed by these systems (Punakivi, 2002; Schulz, 2003; Chopra, 2003.

Figure 1 collapses these concepts into a single diagram, and illustrates the scope of what, in this study, is explicitly termed e-fulfilment, and represents a model for what is currently understood to be an e-fulfilment provider.

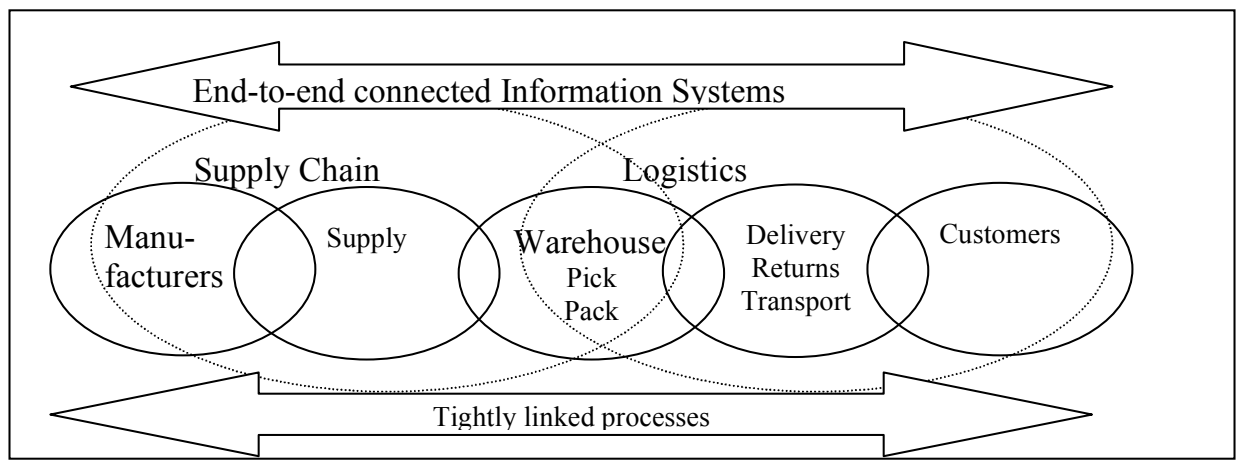

Figure 1: e-Fulfilment Capability Model

This paper reports on the first stage of a longitudinal study into e-fulfilment capabilities and organisational transformation in the logistics industry.

\section{THE STUDY.}

A wave of businesses providing third party (specialised) e-Fulfilment services is apparent throughout Europe and has already gained a significant presence in the UK. This is verified by the annual report produced in the UK by E.logistics Magazine and known as the eFulfilment Index. [e-Fulfilment Index, 2003]. This provided the basis to examine 48 third party e-fulfilment service providers based in the UK. The group of organisations examined are based in a range of locations throughout England and Scotland; mostly in large cities. Their business is largely local in scope, though some organisations offer, or even concentrate on, international deliveries.

These were analysed with respect to relevant features and activities not only as a means of examining a rapidly developing industry, but as a pointer to the future. This study includes an analysis of capabilities based on the operators' reported activities and online web 
assessment. It examines these companies' statements of "unique selling proposition" and desired market as an indicator to their tactical development plans. It also examines capabilities in terms of their degree of transformation. Finally, selected companies are examined to determine their current roles and future strategies.

\section{STUDY RESULTS}

Results from analysis of the 48 UK third party e-fulfilment organisations is presented below.

\section{Current Capabilities}

The range of capabilities offered by the e-fulfilment providers examined is shown in figure 2. These 13 capabilities are in the following categories, which align with aspects of the model outlined in fig 1:

- Capabilities for carrying out physical parts of the fulfilment process. These cover delivery aspects (to homes and in an import/export capacity), "kitting" (delivery with associated installation for items such as phones or computers), picking and packing, rework and relabelling (ie. changing the format of the product), and warehousing. Thus, companies such as New Wave Logistics provide tailored solutions for customers' fulfilment needs, including sophisticated pick \& pack systems.

- Capabilities that link processes. These are enabled by using call centres, and online track/trace capabilities. Though not noted as specific capabilities, extensive information system integration is implied by these facilities. JEM Fulfilment Services is typical in offering full call-centre facilities Computer Telephony Integration (CTI) and online track and trace.

- Capabilities that extend fulfilment into the suppliers' and related providers' value chains. Thus our sample group have wide-spread capabilities to process financial transactions in conjunction with (or even on behalf of) other linked organisations (suppliers and/or customers), direct mail-out functions, product sourcing, "e-tailing" web site hosting, and even technical aspects of web development. Intermail, for example, offers sophisticated web-based "storefront" software it calls "Shop-in-aBox", which is designed to make it easier for clients to offer products online. This group of capabilities becomes the focus later in this paper, of measures of transformation. 


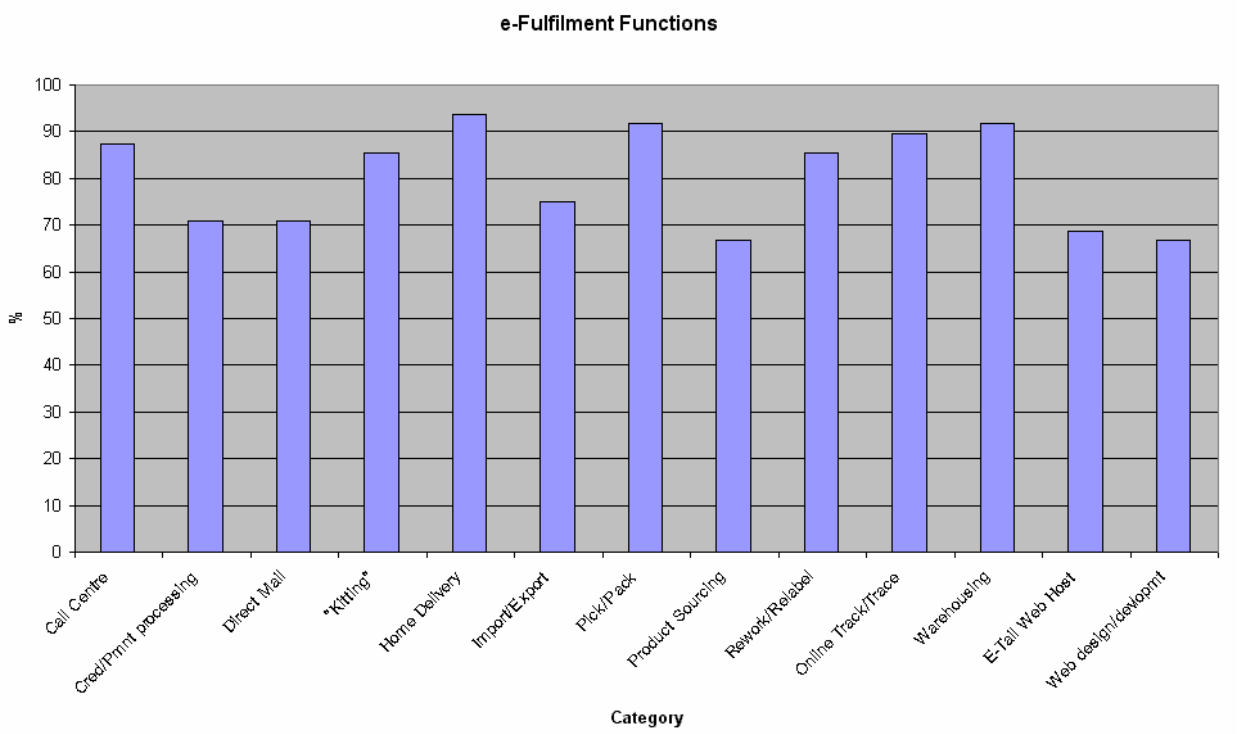

Figure 2: e-fulfilment capabilities

Figure 3 shows the frequency distribution of the number of separate capabilities offered by each of the sample. It is clear from this that there are a minority of specialists, a large group of providers offering a half or more of the possible capabilities, and $30 \%$ of the sample offering all capabilities analysed. We see in fact that many third party providers are seeking to fill all and any aspects of e-fulfilment, which aligns strongly with the capabilities model we present. Those not following this model appear to be specialised in alignment with their parent company's characteristics.

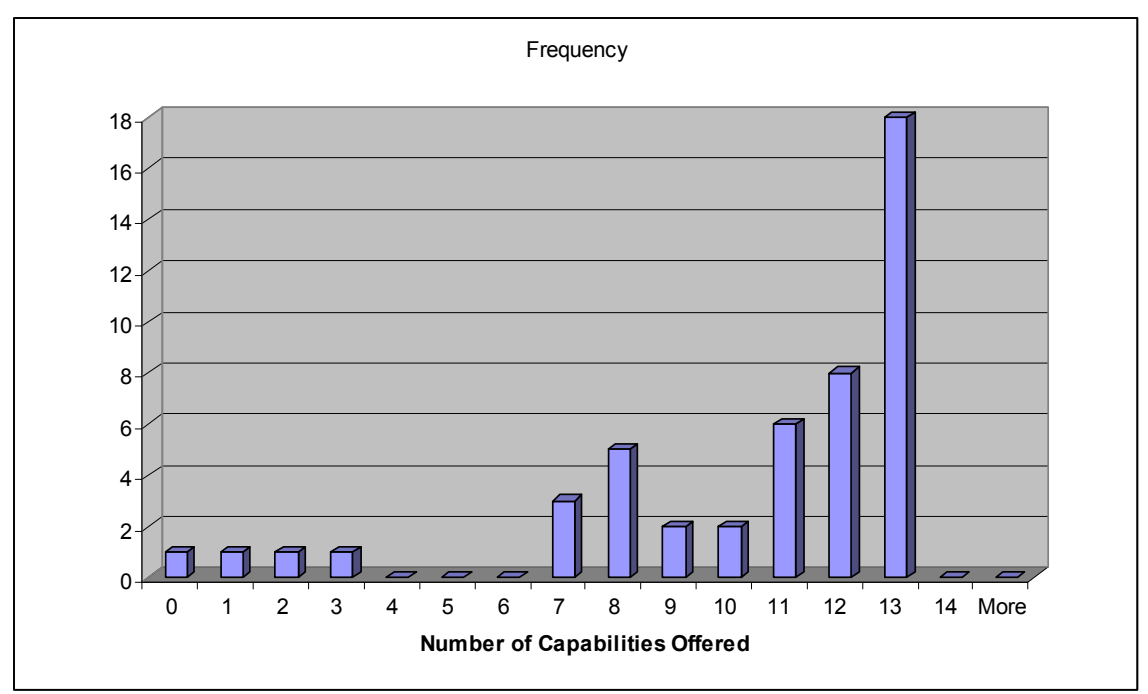

Figure 3. Specialists or Generalists 


\section{Products Delivered}

e-Fulfilment providers show preferences in the products they are prepared to handle. This is shown in figure 4. Most companies are prepared to fulfil CDs, books, clothes, gifts and electronic/electrical. A few specialists exist to service particular product ranges - often tied in with parent-company affiliations. Drinks and health products are surprisingly popular. Furniture and white goods are also popular with some businesses, perhaps those with a prior history of fulfilment in these areas. From these figures, it appears that e-fulfilment providers like small, uniform sized and neatly packaged products. This makes sense as the logistics of storing and delivering them is not only cheaper (eg. CD's take little space), but also more predictable (same size products are easier to cost/process model). They are also able to be delivered to through the standard postal system. Having said this, involvement with heavy-goods is not avoided by e-fulfilment operators, as furniture and whitegoods fulfilment is a major area of interest.

While most of the sampled organisations favour the products already mentioned, few wish to carry food, especially hot food. This is likely due to the need for specialised storage because it is highly perishable, and because it is subject to strict health regulation (Barnett and Alexander 2003). A few specialist carriers will likely service this market using tight operating parameters and specialised equipment.

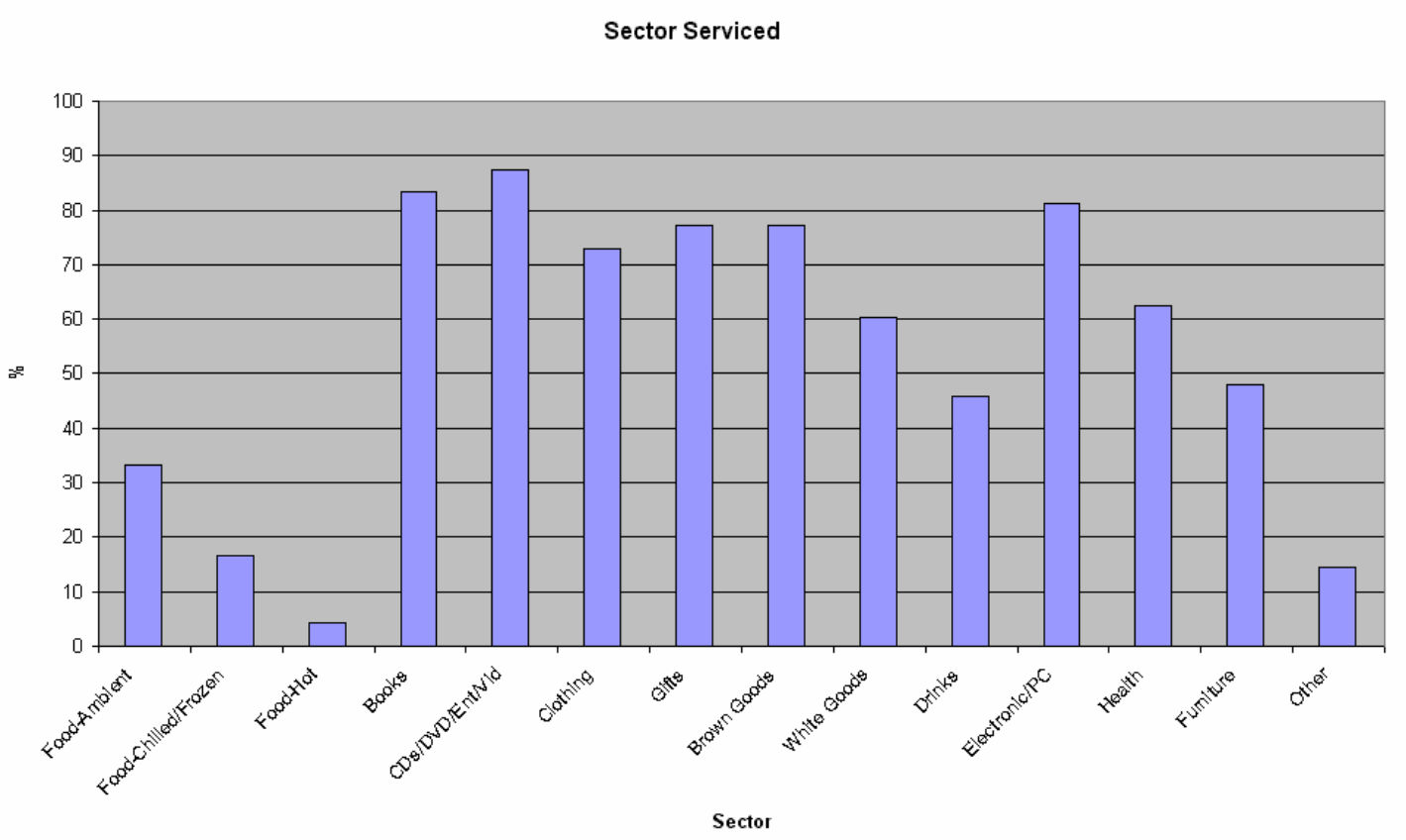

Figure 4. Sectors Serviced.

\section{Last Mile Capabilities and intentions}

Last mile is an area of intense interest with e-fulfilment providers. The capabilities considered (figure 5) all open customer delivery windows, or take advantages of goods reception strategies. Slightly more than $50 \%$ of the sample have already adopted most of 
these capabilities, or are willing to. But tellingly, almost 50\% (almost all the remainder) are considering or are willing to offer these capabilities.

Clearly, as these organisations feel the economic and operating pressures of last mile delivery, their activities in setting up new last-mile-specific solutions is frenetic. The data strongly indicates that the future direction for these businesses will include the provision of last mile capabilities.

\section{Warehouse Space}

Figure 6 shows that most operations have less than 50,000 sqm of warehouse space, with few operators having storage space up to 1,000,000 sqm. As well, many operators have flexible short term arrangements for expanding warehousing facilities to satisfy immediate needs. Because of the short-term turnaround of the deliveries typically undertaken by third party fulfilment operations, warehouses may be effectively replaced by "cross docks", where goods received from suppliers are re-sorted, often simply in a sheltered dock, and immediately placed into vehicles for scheduled delivery. Organisations with large amounts of warehouse space often act as outsourced warehouses for their customers, providing associated benefits of local stocks for customer order fulfilment, product mixing in the distribution system when production is divided among a number of locations, and provision of break-bulk facilities (Cooper and Davis). Again this is noted as a growth area. WarehouseXchange and WhichWarehouse are web-based businesses that provide an unbiased marketplace to find warehouse space. Such marketplaces may also result in warehouse specialists acting as fourth-party outsourcers for e-fulfilment businesses. Indeed, there is a hint of this already in the data.

Last Mile Capabilities

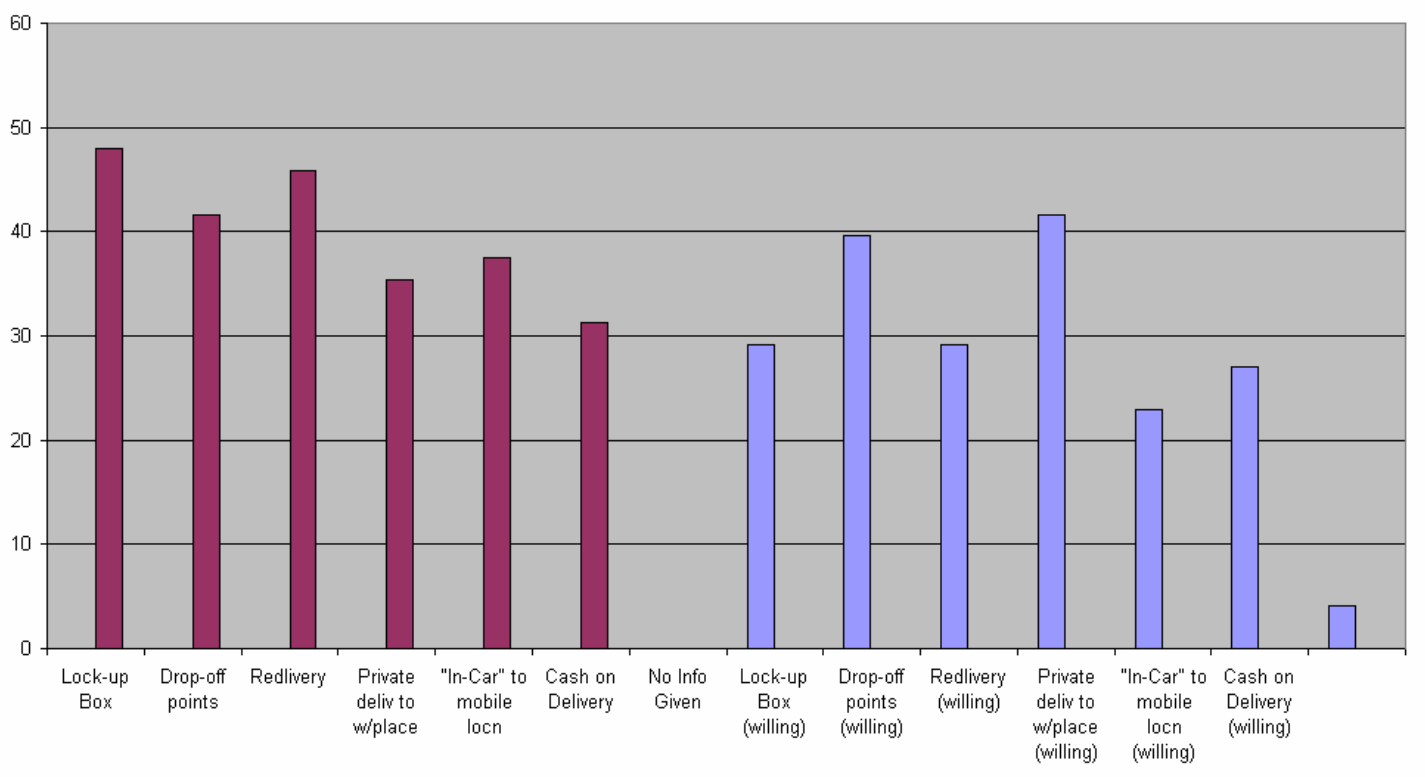

Figure 5. Last Mile Capabilities. 


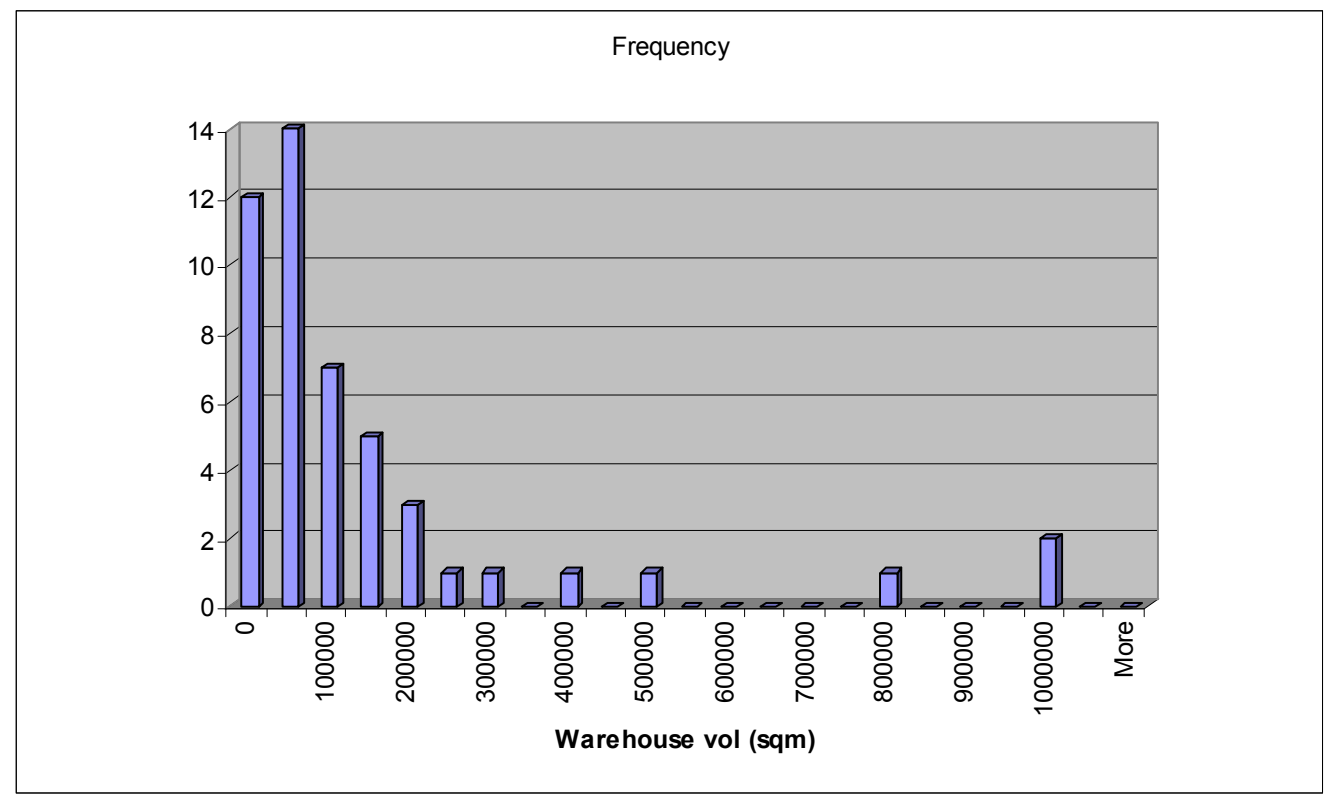

Figure 6. Warehousing Capabilities.

\section{Size and stability of the Businesses}

Most businesses in the sample have turnovers within the $\mathrm{A} \$ 10 \mathrm{M}$ to $\$ 40 \mathrm{M}$ range, with a few much larger (figure 7). These can be considered small to medium sized businesses. Some have the backing of, or are subsidiaries of larger parent businesses. e-Fulfilment companies also appear to have stable market positions, perhaps by virtue of their links to parent companies, but also by providing needed services. The average age of companies studied is 8 yrs, with some being much older (figure 8). This indicates that quite a few must have evolved from traditional fulfilment/transport/warehouse operations to e-fulfilment operations. 


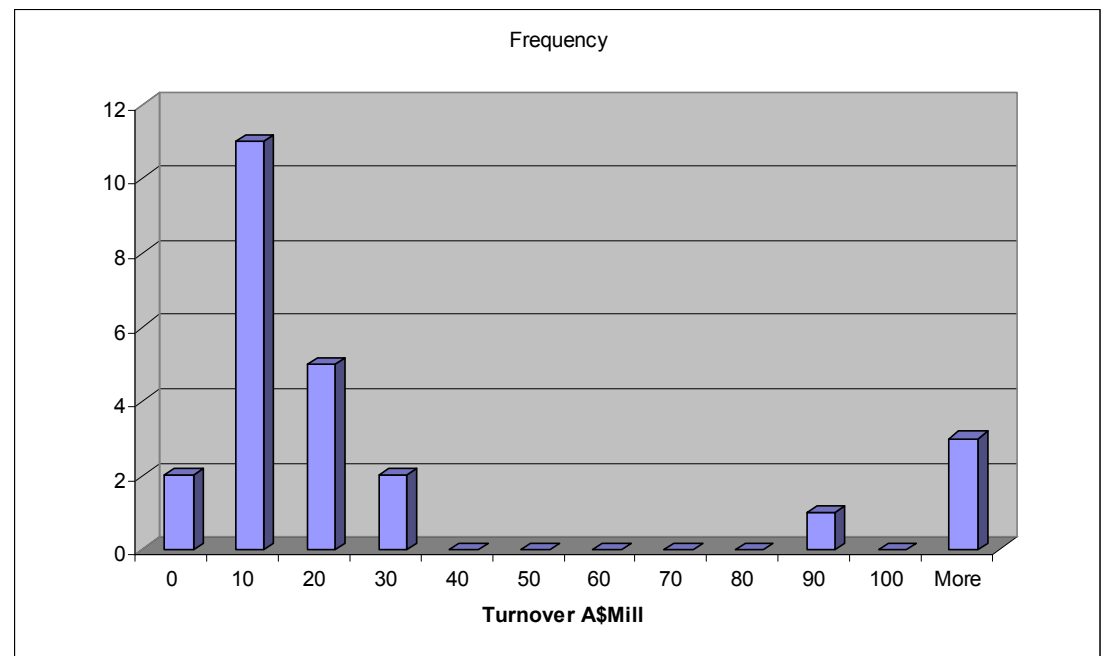

Figure 7. Analysis of Turnover

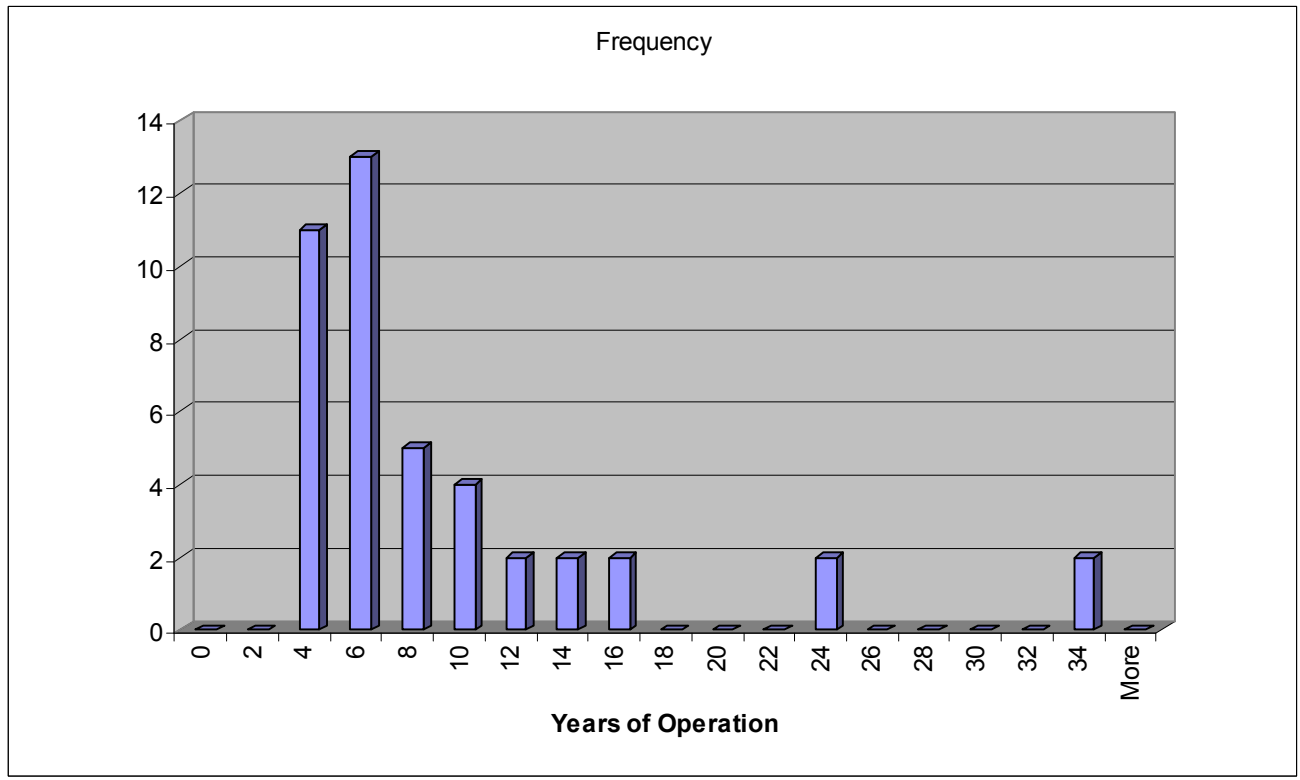

Figure 8. Analysis of Age

\section{Parent Organisations}

While $40 \%$ of third party e-fulfilment providers have been set up independently, $60 \%$ are subsidiaries of other companies, some very large. The nature of the parent companies' activities indicates the businesses have been spun-off to gain revenue in the emerging online market, or perhaps to capitalise on skills and assets of the parent organisation. Some relationships could also indicate a requirement to act as an internal service arm for other 
parts of the business (though it must be emphasised that the entire sample is conducting open business in a free-market environment). In a few cases, they also indicate an attempt to service part of a vertical market in a specialised area. This relationship may result in inherited strengths, product interests, and assets and is an avenue for further research.

\section{Web Development}

Though almost all e-fulfilment providers are derived from, or are in their own right, established logistics/warehouse/transport operators, $68 \%$ are able and willing to provide new services such as web development and hosting facilities. For established logistics providers, this is an interesting development. Not only have these companies implemented the online and web-based changes required to be a credible e-fulfilment provider, but they appear to be keen to offer these services to customers, a phenomenon also observed in the e-grocery environment (Koster 2002). This data clearly indicates new business opportunities in the industry as a whole; an idea that will be developed later in this paper.

\section{TRANSFORMATION OF E-FULFILMENT BUSINESSES: A MODEL}

Over the last decade organisations have been forced to re-examine the role of ICT as a support tool and accept that it has become a major driver for business change (Ash and Burn 2003). e-Business is no longer optional and has become the standard mode of operating not only in financial services, publishing and retail where we have already seen rapid and profitable advancement, but everywhere business is conducted. Indeed new business opportunities have arisen solely based on e-business; and e-Fulfilment is one such example. This has been accelerated with the expansion of logistics operations from primarily a national base to international and global services (Lemoine and Dagnaes, 2003). Based on our research discussed above we can see evidence of a staged transformation taking place within the industry which can be related to a model of e-business change identified by (Deise, Nowikow et al. 2000) - figure 9. This begins with the use of ICT within the parent company (typically transportation or warehousing) to enhance distribution channels through some form of e-commerce. It's followed by the application of ICT within and across value chains, and extending into e-fulfilment.

This inevitably leads to industry transformation as networks of organisations are formed through extended e-business operations; for example, the move we observe within efulfilment companies towards website design activities. Finally, there will be a convergence where many e-fulfilment companies and their offshoots come together and work within the same e-space in virtual environments (Burn and Barnett, 1999; Vlachopolou, 2003; Walters, 2004). One example of this type of transformation can be seen in Zendor, one of the UK's best known names in e-fulfilment, who advertise themselves as 'The Total Distance Selling Solution' offering Logistics, Marketing Services, eBusiness/Interactive Services, Consultancy, Customer Services and Merchandising. As one of their customers now states

'Zendor's competences are N. Brown's competences. That is what we liked: plus their willingness to think and act as a long term partner and respect that this would be a partnership of equals'.

$\mathrm{N}$. Brown is a home shopping giant and the Parent Corporation. Zendor now counts in its client base disparate companies such as Toys R Us, Stanley Casinos, Lloyds TSB 
Screentrade and Sony.

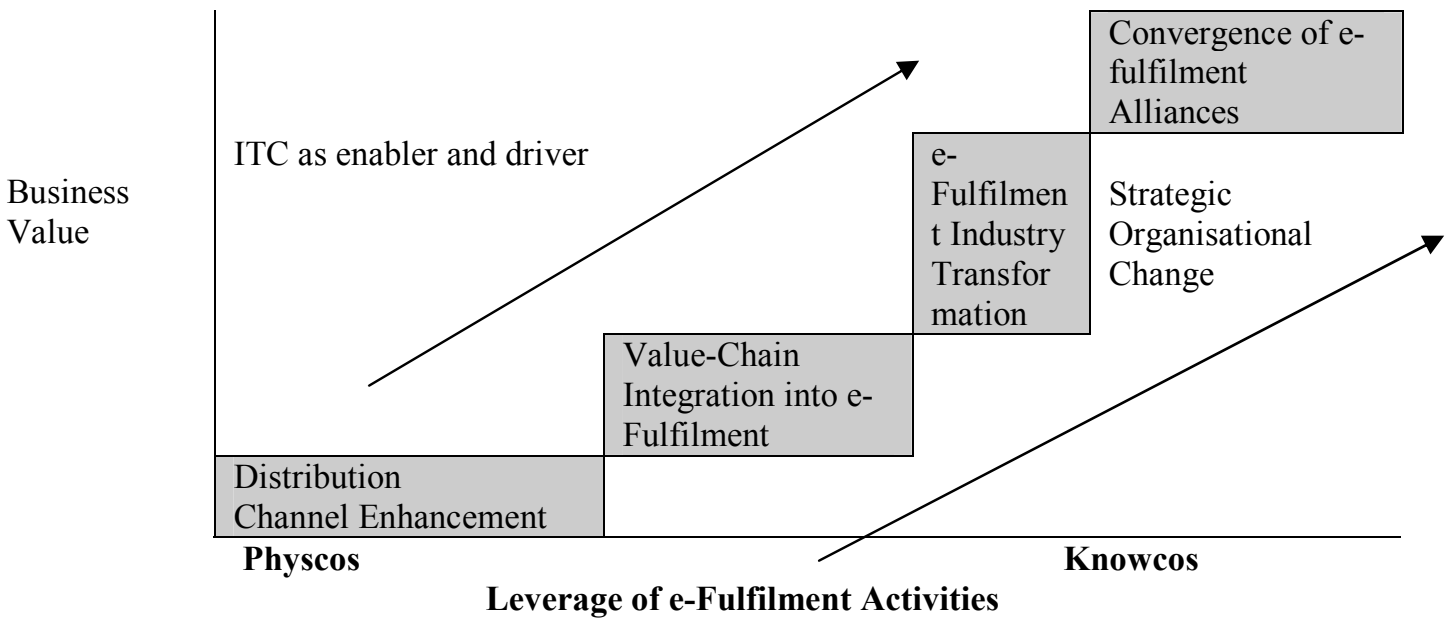

Figure 9: The e-Fulfilment Transformation Model (adapted from Deise, Nowikow et al. 2000).

As e-fulfilment organisations move from left to right across the panorama painted by the Transformation Model (figure 9), they are likely to gain added value but also to encounter much greater risk. As they move through these stages, they will be looking to exploit means of revenue enhancement, cost reduction and relationship management. This transformation can be viewed as the transformation of a company reliant on physical assets to one, which is solely dependent on knowledge assets. As companies collaborate along their value chains the nature of the industry begins to change as organisations decide to outsource some of their traditional functions and focus only on their core competencies. The term "going to market" will no longer be defined as the way a company enters the marketplace but rather it will characterise the way an integrated group of companies creates a set of cascading values to transform the marketplace into a network of value providers. At this stage companies will make a conscious effort to orient their strategies toward becoming knowledge-based "Knowco" or physical goods-based "Physco" companies (Deise, Nowikow et al. 2000). This is not normally a complete transformation but rather an orientation towards one or the other. Knowcos will focus on building brands, capturing ownership of the customer-end market relationship, and investing in knowledge-based core competencies such as emarketing and web services development. They may well expand into providing customer knowledge management services to other companies in their marketplace. Physcos will become hubs of processing expertise. Their success will be based on speed, quality and delivery.

\section{Degree of transformation}

As the discussion on last-mile capabilities indicates, new offerings are being considered by 
e-fulfilment organisations all the time. They appear to be in a highly competitive market place with unmet customer demands offering significant commercial opportunities to be meeting them. The rapid uptake of technology, particularly related to mobile and online, is fuelling rapid change; change that is transformational, not just incremental (Trappey, et al, 2004).

Deise's definitions essentially treat an organisation as providing capabilities, all with the same level of transformation from Physco to Knowco. We see that a transformation model innately requires a heterogenous set of capabilities. It is also clear that each set of these capabilities contributes differently to the degree of transformation; from those that support purely Physco characteristics, such as delivery, to those that are completely concerned with Knowco capabilities, such as retail-web-site consulting services. We wanted to measure the degree of transformation of e-fulfilment organisations.

Thus, we have extended that model to meet these needs (figure 10). In this model we assess the degree of transformation of each of the e-fulfilment organisations' capabilities. Our ongoing research shows that e-fulfilment organisations make conscious decisions about what capabilities they will advance, grow, adopt, shrink and discard. Evidence to be presented in this paper shows that these decisions are made as part of the organisation's strategic planning processes in line with what is anticipated in the future, and tempered by the organisation's culture and perceived overall capabilities.

We propose therefore that degree of transformation is actually made of a portfolio of capabilities, each with a degree of contribution to overall transformation, which consequently determine an organisation's overall degree of transformation.

We focus on capabilities that are externally-facing relative to the e-fulfilment organisation (i.e. Not internal) and make the assessments in two dimensions; the transformation associated with the online retailer (the e-fulfilment organisation's customer), and that associated with the customer's customers (also referred to as the end-customer). We do this because third party e-fulfilment organisations are acting as intermediaries in the supply chain between the end-customers and the online retailers and it is at the two ends of the supply chain that interaction occurs.

By assigning a numerical weighting to the assessment of each capability, we can use the sum of these to quantitatively define (two) measures of transformation for an organisation, even though it has various heterogenous capabilities (figure 10). 


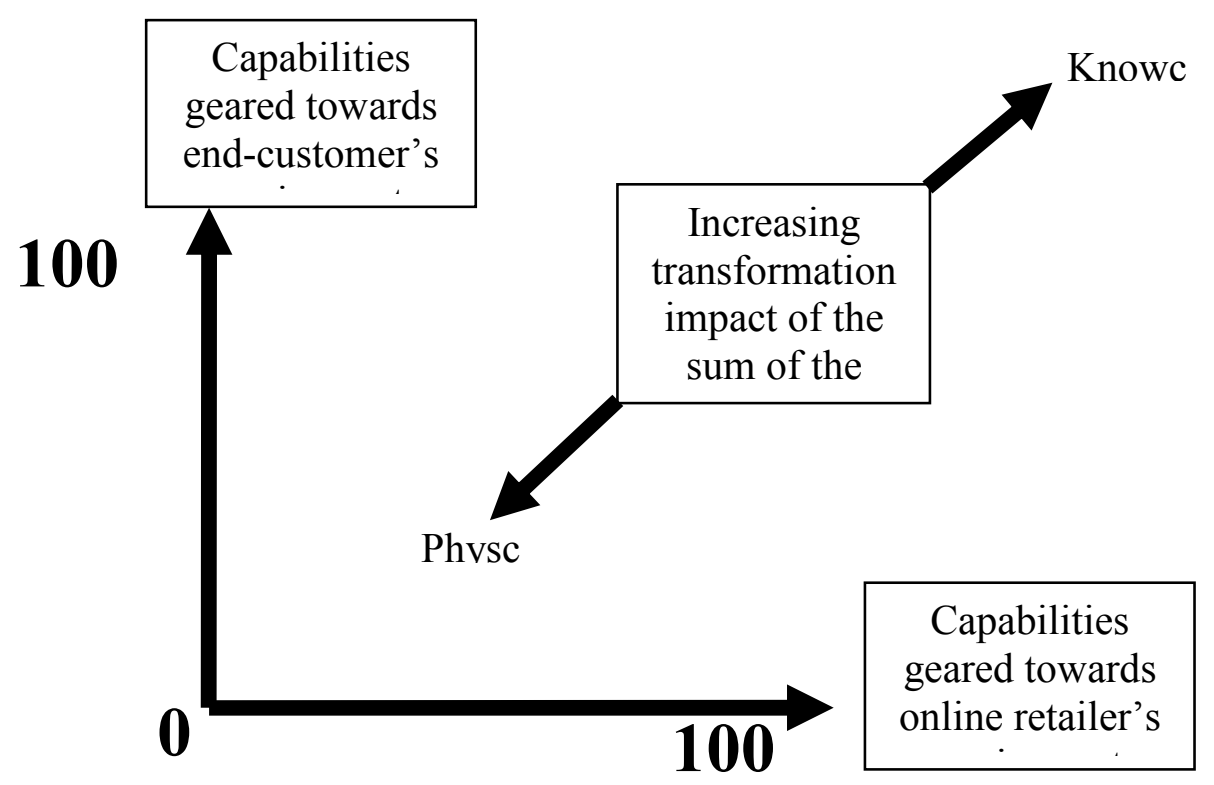

Fig 10: Two-Dimensional Model for Transformation

The following weightings were assigned to each capability for each of the surveyed organisations. (Table II).

\begin{tabular}{|l|l|}
\hline Weighting & Assessment guideline \\
\hline $\mathbf{0}$ & falls into the traditional fulfilment supply chain \\
\hline $\mathbf{1}$ & $\begin{array}{l}\text { fulfilment-related extension of the chain into the business processes of } \\
\text { either end-customer or online retailer }\end{array}$ \\
\hline $\mathbf{2}$ & $\begin{array}{l}\text { major extension into online-retail or end-customer business, including } \\
\text { outsourcing a complete non-fulfilment function }\end{array}$ \\
\hline $\mathbf{3}$ & $\begin{array}{l}\text { completely non-fulfilment business functions performed for end- } \\
\text { customers or online-retailers }\end{array}$ \\
\hline
\end{tabular}

Table II: Method of deriving weightings

Aggregating these weightings with separate measures for "customer-facing" and "endcustomer-facing" capabilities generates a plot point for any e-fulfilment organisation. The original Deise model refers to "stages" of transformation. While we recognise and agree with this assessment, when aggregating capabilities it is quite possible that while the total capability portfolio will place a company clearly into one of the 4 stages of transformation, contributing capabilities may actually relate to other stages. Rather than complicate the model we opt instead to represent the degree of transformation as an index of a baseline value, which is the current maximum for all organisations currently, surveyed. We give this maximum the value of 100 in each dimension. Importantly, this approach allows us not only to measure companies against each other, but also to examine them 
individually or as groups longitudinally over time.

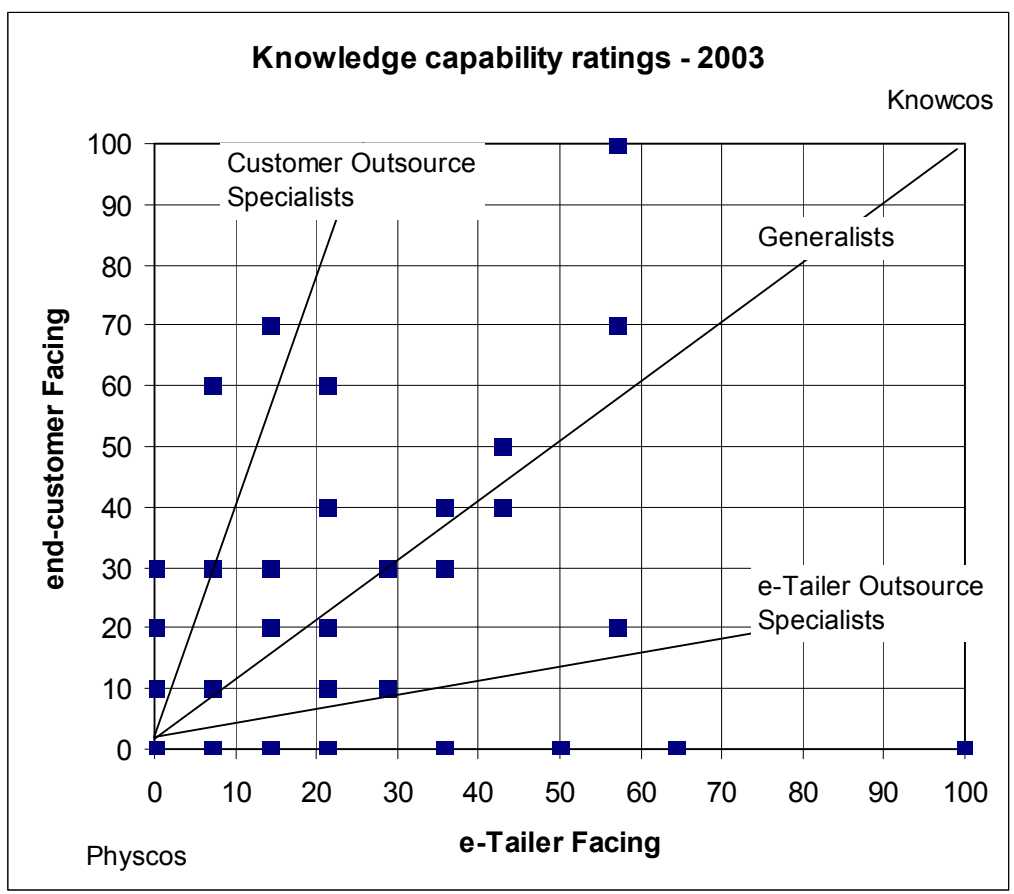

Figure 11: Knowco ratings for capabilities

From this, it appears organisations have followed 3 distinct paths of degree of transformation:

- they confine their transformation to e-tailor-facing capabilities;

- they confine their transformation to end-customer-facing capabilities;

- they develop transformation in both dimensions.

\section{Adapting to changes in environment}

We surveyed a subset of the target companies in depth. We were particularly interested in the companies' perceptions of near-future e-fulfilment challenges and opportunities, whether they were developments of Physco or Knocow capabilities, and how they were preparing for these. The results (Table III) suggest two relatively discrete approaches to the future environment, depending on whether the companies are General Outsourcers (GO) (representing $30 \%$ of e-fulfillers), those providing a full range of capabilities as defined by our e-fulfilment definition, or Niche Outsourcers (NO), targeting a specific market. Whichever category they might fall in, they appear to be comfortable in that approach, with no intentions to alter their customer or geographic focus. 


\begin{tabular}{|c|c|c|c|}
\hline & Item & General Outsourcers & $\begin{array}{l}\text { Niche } \\
\text { Outsourcers }\end{array}$ \\
\hline 1 & $\begin{array}{l}\text { Changes in business } \\
\text { focus }\end{array}$ & \multicolumn{2}{|l|}{ None } \\
\hline 2 & $\begin{array}{l}\text { Geographical ranges } \\
\text { serviced (next } 2 \text { years) }\end{array}$ & \multicolumn{2}{|l|}{ Incremental increases } \\
\hline 3 & $\begin{array}{l}\text { Perception of industry } \\
\text { expansion (next } 2 \\
\text { years) }\end{array}$ & \multicolumn{2}{|c|}{$\begin{array}{l}\text { Most respondents anticipate growth, with about half } \\
\text { suggesting significant growth }\end{array}$} \\
\hline 4 & $\begin{array}{l}\text { development of } \\
\text { capabilities }\end{array}$ & $\begin{array}{l}\text { Hi tech, flexibility, expertise across a } \\
\text { range of capabilities, experience, } \\
\text { expanding range of capabilities }\end{array}$ & $\begin{array}{l}\text { Sector } \\
\text { knowledge, } \\
\text { value-add } \\
\text { capabilities }\end{array}$ \\
\hline 5 & $\begin{array}{l}\text { New capabilities (next } \\
2 \text { years) }\end{array}$ & Customer-facing activities & $\begin{array}{l}\text { Internal } \\
\text { improvements } \\
\text { (transport, etc) }\end{array}$ \\
\hline 6 & $\begin{array}{l}\text { Online services being } \\
\text { supplied }\end{array}$ & Increased significantly in 2 years & $\begin{array}{l}\text { Not increased } \\
\text { much in the next } \\
2 \text { years }\end{array}$ \\
\hline 7 & $\begin{array}{l}\text { Electronic integration } \\
\text { with customers and } \\
\text { customers' customers }\end{array}$ & High and increasing over next 2 years & $\begin{array}{l}\text { Moderate or not } \\
\text { very important }\end{array}$ \\
\hline 8 & Web Site significance & \multicolumn{2}{|c|}{ Seen as highly significant be almost all respondents } \\
\hline 9 & $\begin{array}{l}\text { Web development } \\
\text { outsourcing }\end{array}$ & \multicolumn{2}{|l|}{ Most outsource } \\
\hline 10 & $\begin{array}{l}\text { Intention to increase } \\
\text { web expertise (next } 2 \\
\text { years) }\end{array}$ & Moderate to major increases & Minor levels only \\
\hline 11 & $\begin{array}{l}\text { Biggest concerns }(\text { next } \\
2 \text { years) }\end{array}$ & $\begin{array}{l}\text { Competition from substituted services } \\
\text { (i.e. bricks \& mortar), postal } \\
\text { infrastructure issues, security \& fraud }\end{array}$ & $\begin{array}{l}\text { Postal } \\
\text { infrastructure } \\
\text { issues, security \& } \\
\text { fraud }\end{array}$ \\
\hline 12 & $\begin{array}{l}\text { Main opportunities } \\
\text { (next } 2 \text { years) }\end{array}$ & \multicolumn{2}{|c|}{$\begin{array}{l}\text { Improved customer interfaces, improvements to delivery } \\
\text { infrastructure, online processing }\end{array}$} \\
\hline
\end{tabular}

Table III: Future intentions

The data indicate strong pressures to move to Knowco capabilities in the GOs, with some, but much less perceived imperative, in the NOs, who are more focused on relationships with customers in their sector. This behaviour in turn appears to drive the nature of development of the capabilities. The GOs are developing new customer-facing capabilities while the NOs are more intent on improving internal processes and infrastructure of existing capabilities.

Regardless of their degree of specialisation, they are using, and recognise, the importance of web facilities for their organisations, though it is the GOs who see online services as more significant. They are also more intent on increasing their expertise and developing these capabilities. Interestingly, despite the importance of these services, most organisations are comfortable in outsourcing these. While this is understandable in 
NOs, who do not appear to regard them as so central, it is unexpected, given the GOs' intended direction.

In terms of future environments, e-Fulfilment organisations are anticipating new opportunities generated by new software applications and by delivery infrastructure enhancements (often relating to the Postal Service). When it comes to threats, while all respondents are concerned with security aspects (more particularly, online security issues), GOs are also concerned with substitutable products, which aligns with earlier noted intentions to enhance customer-facing capabilities.

\section{DISCUSSION}

These organisations all targeted online retailers, either primarily, or as a recognised sector of their market. (Duffy and Dale 2002) recognise 10 critical support processes required for success by such retailers, and e-commerce operators in general (Table IV). Of these 10, eight align with capabilities exhibited in our sample (the remaining two cannot be evaluated at this stage). They all have tight end-to-end electronic systems to control their processes, and many provide facilities call centres, payment systems and online components to integrate their services with those of the online retailers.

\begin{tabular}{|l|l|}
\hline $\begin{array}{l}\text { e-Commerce critical success capability, } \\
\text { from (Duffy and Dale 2002) }\end{array}$ & $\begin{array}{l}\text { e-Fulfilment Operator capabilities in } \\
\text { the sample }\end{array}$ \\
\hline Order fulfilment & Yes \\
\hline Revenue generation & No \\
\hline Revenue collection & Last Mile capability \\
\hline Financial control & No \\
\hline IT/Web changes & Yes \\
\hline Business processes & Significant integration \\
\hline e-integration & Yes \\
\hline Order generation & Integrated \\
\hline Call centre integration & Yes \\
\hline $24 / 7$ operation & Enabler \\
\hline Consumer behaviour & Influences customer experience \\
\hline
\end{tabular}

\section{Table IV: Critical e-Commerce Success and e-fulfilment capabilities}

This confirms the critical role of ICT and supporting enterprise systems infrastructure (Sauvage, 2003; Trappey et al, 2004). In most cases, this integration appears to be to the point of providing a single outsourced solution for online retailers' e-fulfilment needs, which in turn appears to result in offerings of diverse sets of services, rather than specialists in particular services. However, there is significant evidence of the e-fulfilment organisations themselves outsourcing certain of their functions to specialists; particularly noticeable with web site aspects of the businesses. In these cases, partner organisations provide those services - likely unnoticed by the ultimate customers. There is strong evidence to suggest that the successful e-fulfilment organisation of the future will be one where online retailer, the e-fulfilment partner, and the specialist e-fulfilment service provider are all cooperating as a virtual organisation (Walters, 2004). 
Our research has identified trends and activities within the UK Logistics industry, and connected them to a capabilities model, which attempts to resolve what "e-fulfilment" actually is. While our results show clear alignment with that model, they also generates a series of questions related to parent-company influence, specialisation incentives, details of online offerings, and other aspects as highlighted in the paper. In assessing degrees of transformation, we have expanded the Deise model to provide a two-dimensional measurement of companies movement towards either a knowledge based capability or physical processing model.

The next stage of the study involves a comparison over three years of transformation followed by a series of case studies, which will be developed through in-depth interviews with 8-10 of these operators.

\section{REFERENCES}

Ash, C. G. and J. M. Burn (2003). Assessing the benefits from e-business transformation through effective enterprise management. European Journal of Information Systems Vol.12 (4): 297-308.

Barnett, M. and P. Alexander (2003). Can e-Grocers survive the last mile? We-B Conference, Perth, Western Australia.

Barsh, J., B. Crawford, B. and Brosso, C. (2000). How e-tailing can rise from the ashes. McKinsey Quarterly 2000(3): 98-109.

Burn, J. M. and Barnett, M. (1999). Communicating for Advantage in the virtual organisation. IEEE Transactions on Professional Communications, 42 (4), 1-8.

Bussiek, T. (1999). The internet-based supply chain - new forms of procurement utilising standard business software. Electronic Markets 9(3): 147-152.

Chopra, S. (2003). Designing the distribution network in a supply chain. Transportation Research 39E(2): 123-130.

Colin, J. (2001). The impact of e-commerce on transport. Joint OECD/ECMT Seminar, Paris.

Cooper, J. C. and M. Davis (1984). Why have a warehouse? Retail \& Distribution Management 12(5): 66-76.

Deise, M. V., C. Nowikow, King, P. and Wright, A. (2000). Executive's guide to ebusiness, PriceWaterhouseCoopers.

DiMaria, F. (2001). FAQs: Is international e-commerce really for you? World Trade 14(9): 36-38.

Duffy, G. and B. G. Dale (2002). E-commerce processes: A study of criticality. Industrial Management \& Data Systems 102(8/9): 432- 440.

e-Fulfilment Guide (2003). Spice Court Publications.

Esper, T. L. and L. R. Williams (2003). The value of Collaborative Transportation Management (CTM): Its relationship to CPFR and information technology. Transportation Journal 42(4): 55.

Greenspan, R. (2003). More spending more. Clickz Stats Retailing, Clickz Network.

Homs, C., Meringer, J. and Rehkopf, F. (2001). Europe's online logistics push, Forrester. August.

Klaus, P. (1998). Supply chain management. Weisbaden, Gabler.

Koster, R. B. M. d. (2002). Distribution structures for food home shopping. International Journal of Physical Distribution \& Logistics Management 32(5): 362.

Lemoine, W. and Dagnaes, L. (2003). Globalisation strategies and business organisation of 
a network of logistics service providers. International Journal of Physical Distribution \& Logistics Management 33(3): 209-228.

Menezes, J. (1999). Baan reinvents self; ERP to e-fulfilment. Computing Canada 25(44): $1-2$.

Punakivi, M. (2001). Solving the last mile issue: Reception box or delivery box? international Journal of Physical Distribution and Logistics Management 31(6): 427.

Punakivi, M. (2002). Increasing the cost efficiency of e-fulfilment using shared reception boxes. International Journal of Retail \& Distribution Management 30(10): 498-507.

Pyke, D., Johnson, M. E. and Desmond, P. (2001). E-fulfilment - It's harder than it looks! Supply Chain Management Review, 5 (1), 26-33.

Rabinovich, E. and P. T. Evers (2003). Product fulfilment in supply chains supporting internet-retailing operations. Journal of Business Logistics 24(2): 205.

Raman, P. (2001). Meeting the demand for e-fulfilment service. Computimes Malaysia.

Rogers, D. S. (2002). Reverse logistics: Trends \& practices. Sao Paulo, Centre for Logistics Management.

Sauvage, T. (2003). The relationship between technology and third-party providers. International Journal of Physical Distribution \& Logistics Management 33(3): 236253.

Schulz, D. (2003). Going the "last mile". Traffic World, Newark.

Shaw, M., Strader, T. J. and Lin, F. R. (1999). The impact of information sharing on order fulfillment in divergent differentiation supply chains. Journal of Global Information Management 7(1): 16-25.

Trappey, A. J. C., Trappey, C. V., Hou, J. L. and Chen, B. J. G. (2004). Mobile Agent Technology and application for online global logistic services. Industrial Management \& Data Systems. 104 (2), 169-183.

Vlachopoulou, M. and Manthou, V. (2003). Partnership alliances in virtual markets. International Journal of Physical Distribution \& Logistics Management 33(3): 254267.

Walters, D. (2004). New economy - new business models - new approaches. International Journal of Physical Distribution \& Logistics Management 34 (3/4): 219-229.

Williams, L. R., Esper, T. L. and Ozment, J. (2002). The electronic supply chain, International Journal of Physical Distribution \& Logistics Management 32(85): 703-719. 